\title{
Therapeutic potential of Indian traditional medicines in Parkinson's disease
}

\author{
Shweta Sharma, K.P. Kochhar , Suman Jain, Rama Jayasundar* and M.R. Divya** \\ Department of Physiology, All India Institute of Medical Sciences, New Delhi-110029, India \\ *Department of NMR, All India Institute of Medical Sciences, New Delhi-110029, India \\ **Department of Neurology, All India Institute of Medical Sciences, New Delhi-110029, India
}

\section{Article Info}

Article history

Received 10 September 2021

Revised 27 October 2021

Accepted 29 October 2021

Published Online 30 December 2021

\section{Keywords}

Bradykinesia

Dopaminergic neurons

Indian traditional medicine

Parkinson's disease

Striatum

Substantia nigra

\begin{abstract}
Parkinson's disease (PD) is second most common neurodegenerative disorder, which is a progressive motor disease that affects 10 million people worldwide and around 5.5 million Indian. The hallmark neuropathology in PD are damage to dopaminergic neurons located in the pars compacta of the substantia nigra (SN) that project to the striatum and alpha synuclein containing inclusion bodies in the surviving neurons, resulting in motor impairments, e.g., tremors, bradykinesia (slow movement), poor balance, rigidity and difficulty in walking, as well as non-motor impairments including constipation, autonomic, psychiatric as well as cognitive impairments. The only pharmacology therapy for PD is levodopa but chronic use of this medicine has many side effects. Hence, these impairments are pressing issues that need to be addressed. This review article attempts to describe the usage of Indian traditional medicines to treat PD. In India, the references to the curative properties of dietary spices in the Rigveda and Atharvaveda arguably seem to be the earliest records of the use of herbs in medicine.
\end{abstract}

\section{Introduction}

Parkinson's disease is termed after Dr. James Parkinson, the surgeon who first defined it as "shaking paralysis" in 1817 (Houghton and Howes, 2005). It is only in last few decades that some breakthrough in development of specific therapies has been made to treat PD patients since the first patient was diagnosed with Parkinsonian syndrome. The aim of this review is to discuss the current therapeutic strategies, their limitations along with Indian traditional remedies used to treat $\mathrm{PD}$.

The pathological hallmarks of PD are Lewy bodies whose main constituent is alpha-synuclein, a presynaptic neuronal protein. Interestingly, $\alpha$-synuclein has a unique importance in aetiology of PD because it appears to link familial and sporadic forms of the disease. The proteostasis of alpha-synuclein is disturbed in PD suggested after investigating the presence of aggregates in patient brain (Fink, 2006; Lashuel et al., 2013). It was discovered in the 1960s that dopamine imbalance in the striatum is responsible for motor symptoms of PD. Dopamine connects the substantia nigra and the corpus striatum to regulate muscle activity. PD is characterized by progressive dopminergic neurons in pars compacta in the substantia nigra that leads to cardinal motor symptoms of PD, i.e., rigidity, resting tremor and bradykinesia. The voluntary movements, gait coordination and postural maintenance, movement sequencing, habitual behaviours and autonomic activity are all affected through varying degrees of dopamine. Deterioration of the

Corresponding author: Dr. K.P. Kochhar

Associate Professor, Department of Physiology, All India Institute of Medical Sciences, New Delhi-110029, India

E-mail: kpkochhar06@gmail.com

Tel.: +91-9871859100

Copyright (c) 2021 Ukaaz Publications. All rights reserved.

Email: ukaaz@yahoo.com; Website: www.ukaazpublications.com neurons that discharge dopamine causes a disparity of inhibitory (dopamine) and excitatory (acetylcholine) neurotransmitters in the region. This imbalance induces excessive repetitive uncontrollable movements, called dyskinesis, and absence of movement, known as gait freezing (Bloem et al., 2004; Olanow et al., 2009; and Devos et al., 2010).

As we know, PD is also an age-related neurodegenerative disorder where patients experience non-motor symptoms including fatigue, constipation, cognitive deficits, sleep disturbance, altered mood and pain. In this disease, over time the symptoms become worse, due to neuronal damage and emergence of interruptions in the blood brain barrier (BBB), caused by neurotoxic components released after the activation of glial cells. This loss of integrity of BBB generates a current of lymphocytes in the brain which ultimately leads to prolonged inflammatory reactions, responsible for neuronal damage (Dzamko et al., 2014).

The commonly used drug is levodopa for the treatment of PD. It suppresses some of the motor symptoms and compensates for dopaminergic cell loss by enhancing dopamine synthesis in the remaining terminals. Despite years of using levodopa (L-dopa), current treatment options for PD are largely ineffective to reverse or prevent pathological outcomes. Because longterm levo-dopa treatment often causes dyskinesis, motor fluctuations, and psychiatric disturbances (Schneider et al., 2003); alternatives in the form of herbal medicines and traditional system of medicines have also been explored (Nagashayana et al., 2000; Chen et al., 2007; and Li et al., 2011). Several reports have shown that a number of herbal remedies possess neurotrophic and neuroprotective properties in PD-related models (Kim et al., 2009; Hu et al., 2011; Mu et al., 2011; Xu et al., 2013; Gaur et al., 2013). 
In this context, traditional Indian medicines have been revisited to determine whether their primary or adjunct form is more effective and/or less toxic.

\section{Mode of action and disadvantage of the current pharmacolo-gical strategy}

Conventional treatments for Parkinson's disease have included levodopa, dopamine agonists, and anticholinergics (Connolly and Lang, 2014). In the early stages of the disease, dopamine replacement therapy, using the dopamine precursor levodopa, is effective, but the dose response decreases with disease progression, and motor complications (dyskinesias) and other side effects (e.g., mood disorders and sleep disturbances) arise after chronic treatment. These complications may be due to either the advanced stage of the disease (in which degenerating dopaminergic neurons cannot buffer the fluctuating plasma levels of levodopa, resulting in pulsatile stimulation of the dopamine receptors) or the further degeneration in non-dopaminergic regions (Cui et al., 2005). L-DOPA, however, carries several side effects, viz. It does not prevent dopaminergic neuron degeneration as well as it has no effects on non-motor symptoms (Olanow et al., 2006; Cenci, 2014; Tosi et al., 2016) and simultaneously prolonged use of levodopa can lead to levodoparesistance ultimately leads to dyskinesia (Blasi et al., 2007). Levodopa is also responsible for PD-associated GI dysfunction in PD patients (Sun et al., 2008; Kango et al., 2013). Since the underlying mechanisms of neuronal loss in patients are not known, current therapies are mainly symptomatic and not curative or preventive (Poewe et al., 2010; Zhang et al., 2014). Levodopa significantly restored the cell proliferation (PCNA cells) in the SVZ of 6-OHDA-lesioned rats, again pointing to an important role of dopamine in increasing adult neurogenesis (Höglinger et al., 2004) Studies with dopamine receptor agonists and antagonists suggest that dopamine directly interacts with the neural precursor pool. Administration of the selective dopamine D2 receptor (D2L) agonist ropinirole increased the number of PCNA-expressing cells at both the lesioned and non-lesioned sides (Höglinger et al., 2004). However, this effect can be due to changes in the proliferation or the survival. In an elegant study, it was proven that intraventricular infusion of a D3 receptor agonist (7-hydroxy-N,N-di-npropyl-2aminotetralin [7-OH-DPAT]) resulted in more BrdU labeled cells in SVZ and RMS of rats (Van et al., 2004). In mice, the same D3 receptor agonist failed to induce proliferation, pointing to species difference in dopamine receptor expression (Baker et al., 2005). However, the ability of these drugs to cross blood brain barrier and reach the brain for their action is still very low, hence traditional drugs with few side effects are of high priority and urgently needed. Currently, new therapeutic strategies have been introduced, which comprise traditional medicines and the use of new drug molecules and/or new delivery systems, increasing the therapeutic action while reducing adverse effects (Stayte and Vissel, 2014).

\section{Indian traditional medicine}

For centuries, the primary source of medicine are the agents derived from natural sources especially the plants because of their affordability, safety, long term use (Singh, 2007). All the evidences suggest that $>70 \%$ of the current drugs are derived from plants (Newman and Cragg, 2012) and furthermore $>50 \%$ of the worldwide population relies on plants for their healthcare. Plants have the ability to produce wide range of secondary metabolites which are useful in disease prevention and treatments purposes. These secondary metabolites include alkaloids, stilbenoids, saponins, glycosides, steroidal lactones, bilobalide, caffeine, xanthones, isoflavonoids, catechins, anthocyanins, thymocyanin, sallylcysteine, oligosaccharide esters, and some of these have neuroprotective potential due to which they can be used against PD (Singh et al., 2005; Hatti et al., 2014). Flavonoids (polyphenol group consists of aromatic rings with a phenolic hydroxyl group and a 3-OH), a group with strong antioxidant (scavenge free radicals and reactive oxygen species) and iron-chelating properties, are categorized into flavones, flavonones, isoflavones, flavonols and anthocyanidins based on their glycation, hydroxylation and alkylation patterns (Spencer, 2009). Along with their antioxidant properties, the feasible mechanism of action of flavanoids is the association of flavanoids with neuronal signaling cascades such as protein Kinase C, MAPK and PI3K/Akt, this association increase neuronal survival by decreasing apoptosis (Spencer, 2009). They can cause neurogenesis and angiogenesis and have the ability to function directly against neurotoxic agents and pro-inflammatory agents (Vafeiadou et al., 2007). Since oxidative stress is believed as major cause of dopaminergic neuronal failure in substantia nigra, so the molecules with antioxidative properties decrease the excitotoxicity, are of primary importance (Kedar, 2003; Dawson and Dawson, 2003; Schapira and Olanow, 2004).

Many medicinal plants contain constituents which have beneficial effects against PD. Across the world, phytomedicine, herbs and spices have long been recognized for their unique and beneficial advantages which are anticonvulsant, antidepressant, antianxiety, sedative, improving locomotor function, and memory enhancing effects (Kochhar, 2008; Kochhar, 2008; Kumar and Khanum, 2012). While most herbal products and their active ingredients have been examined in vivo for PD models; some have only been studied in cell models to date (Noelkar et al., 2005; Chan et al., 2009). In many neurodegenerative diseases, such as Parkinson's disease, dementia, stress, and fatigue, medicinal plants have also shown beneûcial effects (Gao et al., 2009; Kumar and Khanum, 2012; Al-Snafi, 2015). The available evidences of use of traditional medicines and their possible bioactivities are listed as follows:

\subsection{Azadirachta indica $\mathrm{L}$.}

A. indica is also referred to as neem (Figure 1. A), which means it provides freedom from all diseases (Gupta et al., 2017), and it is used for thousands of years in Indian continent. All the parts of this plant, including leaves, bark, seeds and flowers have been used to treat both acute and chronic human diseases as an antimicrobial, larvicidal, antimalarial, antiviral, antibacterial, insecticide and spermicidal (Gupta et al., 2017). Neem belongs to Maliaceae/ Mahogany family and this plant can be used to cure multiple acute and chronic diseases.

\section{1. (a) Chemistry of $A$. indica}

Till date over 300 phytochemicals have been isolated from neem, hence it is considered as 'storehouse' of several phytochemicals, these phytochemicals are structurally complex and chemically diverse (Biswas et al., 2002; Subapriya and Nagini; 2005; Siddiqui et al., 2009). Majorly two classes of phytochemicals have been isolated from different parts of neem, i.e. (i) isoprenoids and (ii) non-isoprenoids. The most common isoprenoids are triterpenoids, vilasinins, linonoids, C-secomeliacins and diterpenoids and non- 
isoprenoids are polysaccharides, polyphenolics, proteins, sulphur compounds, tannins, coumarin and aliphatic compounds (Biswas et al., 2002; Brahmachari, 2004). 0.13\% essential oil is possessed by neem leaves which is responsible for the smell of leaves (Rex $e t$ al., 2019). Other phytochemicals derived from neem, which possess therapeutic roles are: azadirachtin, axadiradione, azadirone, nimbolide and gedunin.

Table 1: Neuroprotective effects of various medicinal plants extracts, their active constituents and mechanism of actions in various neurological disorders

\begin{tabular}{|c|c|c|c|c|c|c|}
\hline Plants & $\begin{array}{l}\text { Botanical } \\
\text { name }\end{array}$ & \begin{tabular}{|l} 
Plant \\
part
\end{tabular} & \begin{tabular}{|l} 
Bioactive \\
compounds
\end{tabular} & $\begin{array}{l}\text { Neurological } \\
\text { disorders }\end{array}$ & $\begin{array}{l}\text { Mechanism of } \\
\text { action }\end{array}$ & \begin{tabular}{|l} 
Other \\
biological role \\
\end{tabular} \\
\hline \multirow[t]{2}{*}{ Neem } & $\begin{array}{l}\text { Azaradichta } \\
\text { indica }\end{array}$ & & Deoxygedunin & $\begin{array}{l}\text { Parkinson's } \\
\text { disease }\end{array}$ & $\begin{array}{l}\text { Improved the behavioral } \\
\text { performance and reduced } \\
\text { dopaminergic neurons loss } \\
\text { in substantia nigra in } \\
\text { Parkinson's disease models }\end{array}$ & $\begin{array}{l}\text { Anti-proliferative, } \\
\text { anti-inflammatory }\end{array}$ \\
\hline & & Leaf extract & $\begin{array}{l}\text { Meliacin- } \\
\text { nimbolide, } \\
\text { quercitine, } \\
\text { kaempferol }\end{array}$ & $\begin{array}{l}\text { Parkinson's } \\
\text { disease }\end{array}$ & $\begin{array}{l}\text { Neem leaf extract suppresses } \\
\text { radiation-induced NF- } \mathrm{KB} \\
\text { activation and increases } \\
\text { caspase activity and cell } \\
\text { death }\end{array}$ & \\
\hline Karela & $\begin{array}{l}\text { Momordica } \\
\text { charantia }\end{array}$ & $\begin{array}{l}\text { Momordica } \\
\text { charantia } \\
\text { Polysaccharides }\end{array}$ & $\begin{array}{l}\text { Linolenic, } \\
\text { momordicine, } \\
\text { phenol, } \\
\text { flavonoid and } \\
\text { vitamin }\end{array}$ & $\begin{array}{l}\text { Parkinson's } \\
\text { disease }\end{array}$ & $\begin{array}{l}\text { MCPs can regulate the } \\
\text { activation state of the } \\
\text { TLR4/MyD88/NF- } \kappa B \\
\text { pathway, exert protective } \\
\text { effects, improve brain } \\
\text { function }\end{array}$ & $\begin{array}{l}\text { Antiviral, } \\
\text { antioxidative }\end{array}$ \\
\hline \multirow[t]{4}{*}{ Ashwagandha } & $\begin{array}{l}\text { Withania } \\
\text { somnifera }\end{array}$ & Root extract & $\begin{array}{l}\text { Alkaloids, } \\
\text { withanolides, } \\
\text { sitoindosides } \\
\text { Withanolide A } \\
\text { and B, } \\
\text { Sominone, } \\
\text { Withanone, } \\
\text { Witheferin A, } \\
\text { Withanoside 4 } \\
\text { and 5, } \\
\text { Withanolide Q } \\
\text { and Ashagand- } \\
\text { hanolide } \\
\end{array}$ & $\begin{array}{l}\text { Parkinson's } \\
\text { Disease }\end{array}$ & $\begin{array}{l}\text { - Attenuated against } \\
\text { 6-OHDA toxicity } \\
\text { - Improved catecholamines } \\
\text { in MPTP induced by } \\
\text { parkinsonism } \\
\text { - regulated D2 dop } \\
\text { aminergicreceptor numbers } \\
\text { instriatum } \\
\text { - reduced oxidative } \\
\text { impairments and restored } \\
\text { mitochondrial respiratory } \\
\text { chain enzymes }\end{array}$ & $\begin{array}{l}\text { Antiplatelet } \\
\text { aggregatory, } \\
\text { anxiolytic, } \\
\text { anticonculsive, } \\
\text { anti-inflammatory }\end{array}$ \\
\hline & Leaf extract & & & $\begin{array}{l}\text { Parkinson's } \\
\text { Disease }\end{array}$ & $\begin{array}{l}\text { - Reduced the oxidative } \\
\text { damage and modulated } \\
\text { physiological } \\
\text { abnormalities }\end{array}$ & \\
\hline & $\begin{array}{l}\text { Aqueous } \\
\text { extract }\end{array}$ & & & $\begin{array}{l}\text { Cognitive and } \\
\text { motor } \\
\text { coordination } \\
\text { impairments }\end{array}$ & $\begin{array}{l}\text { Regulated expression of } \\
\text { synaptic proteins involved } \\
\text { in synaptic plasticity and } \\
\text { neuronal cell survival }\end{array}$ & \\
\hline & $\begin{array}{l}\text { Root powder } \\
\text { extract }\end{array}$ & & & $\begin{array}{l}\text { Parkinson's } \\
\text { Disease }\end{array}$ & $\begin{array}{l}\text { Decreased rotenone induced } \\
\text { toxicity levels }\end{array}$ & \\
\hline Pipalli & Piper longum & Seed extract & $\begin{array}{l}\text { Alkaloids, } \\
\text { Piperine, Pi- } \\
\text { perluguminine }\end{array}$ & $\begin{array}{l}\text { Parkinson's } \\
\text { Disease }\end{array}$ & $\begin{array}{l}\text { Showed neuroprotective } \\
\text { effects in an MPTP induced } \\
\text { chronic mouse model of PD }\end{array}$ & $\begin{array}{l}\text { Antioxidative, } \\
\text { anti-inflammatory, } \\
\text { antianxiety }\end{array}$ \\
\hline
\end{tabular}

\section{1. (b) Biological role of $A$. indica}

It was demonstrated (Gupta et al., 2010) that the neem derived nimbolide possess potential to inhibit pro-inflammatory transcription factor, nuclear factor (NF)- $\mathrm{BB}$ signaling pathway, as it is well known that NF- $\mathrm{KB}$ regulate expression of genes that contribute to proliferation, angiogenesis etc. Acomprehensive review of the molecular targets of neem components can be found in previous articles published by many researchers (Hao et al., 2014; Patel et al., 2016). One derivative of gedunin, i.e., Deoxygedunin binds with TrkB receptor and activates TrkB and its downstream molecules in a brain-derived neurotrophic factor (BDNF)independent manner. Both in vivo and in vitro studies have demonstrated neem's and its derivatives' neuroprotective effects. One study was aimed to examine the neuroprotective effects of deoxygedunin in 6-hydroxydopamine (6-OHDA)-lesioned rat model 
and 1-methyl-4-phenyl-1,2,3,6-tetrahydropyridine (MPTP)induced mice model of Parkinson's disease. Deoxygedunin $(5 \mathrm{mg} /$ $\mathrm{kg}$ ) was administered to the rats for one month intra-peritoneal. The treatment with deoxygedunin was started either two weeks before (pre-treatment) or two weeks after (post-treatment) in the 6-OHDA lesion. The isovolumetric vehicle was used as control and normal. Mice were given deoxygedunin $(5 \mathrm{mg} / \mathrm{kg}$, i.p.) for 2 weeks and with MPTP twice $(20 \mathrm{mg} / \mathrm{kg}$ i.p.) on day 7 . Deoxygedunin improved the behavioral performance and reduced dopaminergic neurons loss in substantia nigra in Parkinson's disease models. These observations were accompanied with the activation of TrkB receptors and associated signaling molecules such as phosphatidylinositol 3-kinase (PI3K) and mitogen-activated protein kinase (MAPK). These observations suggest the neuroprotective properties of deoxygedunin (Nie et al., 2015).

\subsection{M. charantia}

M. charantia (Figure 2), also known as bitter gourd or bitter melon, has long been regarded as a food and medicinal plant. It is an important edible plant with medicinal properties widely distributed throughout the Asia. M. charantia belongs to Cucurbitaceae family. Bitter gourd is a powerful nutrient-dense plant composed of a complex array of beneficial compounds. As a natural compound in daily food, M. charantia polysaccharides (MCPs) are famous for their antidiabetic, antioxidant, antitumor, anti-inflammatory, and hypoglycemic (Jia et al., 2017); however, little is known about its role from the perspective of neurogenesis regulation. Studies have been done and it is proved that MCPs can protect nerve damage following stroke via scavenging free radicals (Gong et al., 2015). It is also found (Gong et al., 2015) that MCPs can play a protective role in neurological diseases and injuries. In the view of potential use of bitter gourd fruit in the traditional medicine, its therapeutic benefits and bioactive compounds warrant further investigation.

\section{2. (a) Chemistry of Momordica charantia}

M. charantia include vitamins, minerals, antioxidants and bioactive chemicals, and these all contribute to its remarkable versatility in treating a wide range of illness and neurodegenerative diseases. Bitter gourd fruit contain high amounts of Vitamin B-complex, vitamin $\mathrm{A}$, vitamin $\mathrm{C}$ as well as vitamin $\mathrm{E}$ due to which, they possess antioxidative, antiviral, antimicrobial activities, hence used as very popular traditional medicine in India for various diseases. All the medicinal value of bitter melon has been attributed to its high antioxidative properties due to presence of flavonoids, isoflavones, phenols, terpens, glucosinolates and anthroquinones, all of these also confer a bitter taste (Snee et al., 2011). It has also other very important health promoting substances such as charatine, polypeptide-p and vicin (Kumari et al., 2017). MCPs account for about $6 \%$ of $M$. charantia powder, which are heterosaccharides composed of glucose (Glu), rhamnose (Rha), mannose (Man), arabinose (Ara) and galactose (Gal) (Yan, 2021). Some scientist isolated acidic branched heteropolysaccharide, from bitter melon, which mainly consisted of Rha, Glu, Gal, xylose (Xyl), Man, Ara and galacturonic acid (GalA). It has antioxidant and inhibitory properties (Tan and Gan, 2016). Recently (Xu et al., 2015), a watersoluble polysaccharide is isolated from the fruit of bitter gourd, mainly composed of Gal, Rha, Ara and Xyl, have significant hypoglycemic effect.

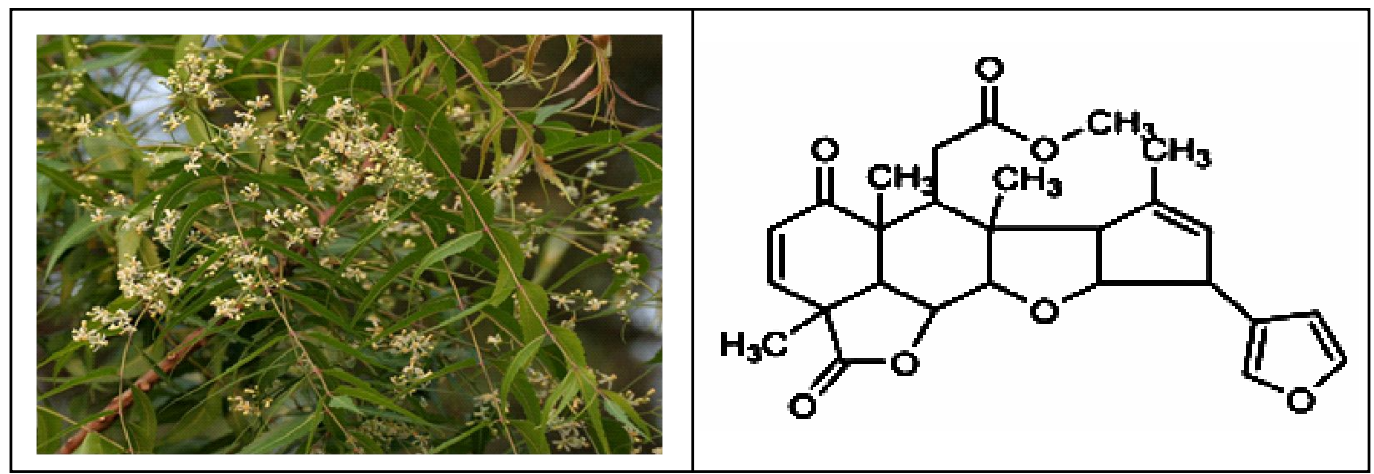

Figure 1: (A) Neem and (B) Nimbodine.

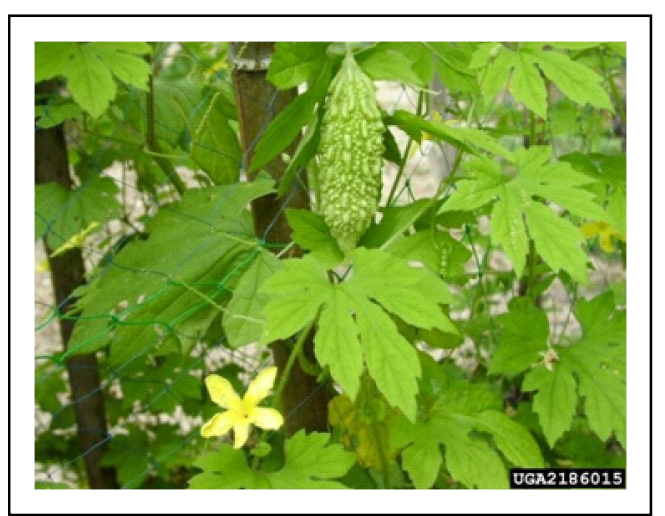

Figure 2: M. chrantia. 


\section{2. (b) Biological role of M. charantia}

The natural antioxidants of bitter gourd, polyphenolic compounds and phenols, have the ability of chain breaking antioxidants and proposed to protect against the damage caused by free radicals to cell membrane, cell component and DNA (Dziri et al., 2012). Bitter gourd is considered as one of the best diseased preventive foods, based on its potential and diversified effects (Amagase, 2006). Guo et al. (2021) recently investigated the potential role of MCPs in PD and reveal the molecular mechanism of its function in vitro and in vivo. In this study, it was found for the first time in animal and cell models of PD, those MCPs have antioxidant, anti-inflammatory, and antiapoptotic effects. In terms of anti-inflammatory response, this study detected the expression levels of inflammatory factors TNF- $\alpha$ and IL- $1 \alpha$ in brain striatum tissue. In summary, this study found that in the PD model, MCPs can regulate the activation state of the TLR4/MyD88/NF-kB pathway, exert protective effects such as anti-inflammatory, antioxidative stress, and antiapoptosis, improve brain function, and provide a new method for the treatment of PD. This study confirmed that MCPs have protective effects on MPTP- and MPP+- induced PD models in mice and cells. It was found that MCPs can reduce the damage of MPTP to mice's coordination and exercise ability; it also inhibits the production of inflammatory factors and oxidative stress products in brain, thereby increasing the level of dopamine. In in vivo study, MCPs found to inhibit MPP+- induced apoptosis and oxidative stress, and also MCP exerts a protective effect by inhibiting the activation of the TLR4/MyD88/NF-kB pathway (Guo et al., 2021). It was proved that MCPs can improve oxidative stress, inflammation, apoptosis and hyperlipidemia during myocardial infarction by inhibiting the NF-кB signaling pathway (Raish, 2017). In a study (Kang et al.,
2017), they concluded that MCPs also have the ability to increase total volatile fatty acid production, regulate rumen fermentation pathways, and hence affect the number of cellulose-decomposing bacteria. It is known that PD is related to oxidative stress, inflammation, and apoptosis (Dexter and Jenner, 2013). MPTP can induce the decrease of GSH and SOD levels in the mouse striatum and the increase of MDA levels. The treatment of MCPs can reverse the changes of these factors, suggesting that MCPs have antioxidant effects. It is also known that cytochrome $\mathrm{C}$ is a signal molecule necessary for the death of apoptotic cells. It was once found in alcoholic gastritis that MCPs can improve mucosal oxidative stress, apoptosis and inflammation by inhibiting the activation of the NF$\kappa \mathrm{B}$ signaling pathway (Raish et al., 2018).

\section{Withania somnifera (L.) Dunal}

Withania somnifera (L.) (Figure 3. A) Dunal is widely used in Indian systems of medicine (ISM) due to its exceptional pharmacological properties such as antistress, memory enhancer, nerve tonic and adaptogen with hypoglycemic and hypolipidemic effects. W. somnifera belongs to Solanaceae family. It is also lnown as "Indian Winter Cherry" or "Indian Ginseng" in English, as "Asgand" in Urdu and as "Ashwaghandha" in Sanskrit, it is an important herb in India (Amantea et al., 2009). It also used against insomnia, infertility, cognitive deficits, gout, infectious diseases and rheumatoid arthritis over thousands of years and it also has shown to be helpful in learning and memory (Van et al., 2004). The formulations of ashwaghandha are mainly used in Ayurvedic and Unani system of medicine due to its medicinal properties and is stated as an approved drug by Indian Pharacopoeia (1985) and it is a century old herbal Rasayana which is used to treat neuronal ailments (Singh et al., 2011; Uddin et al., 2012).

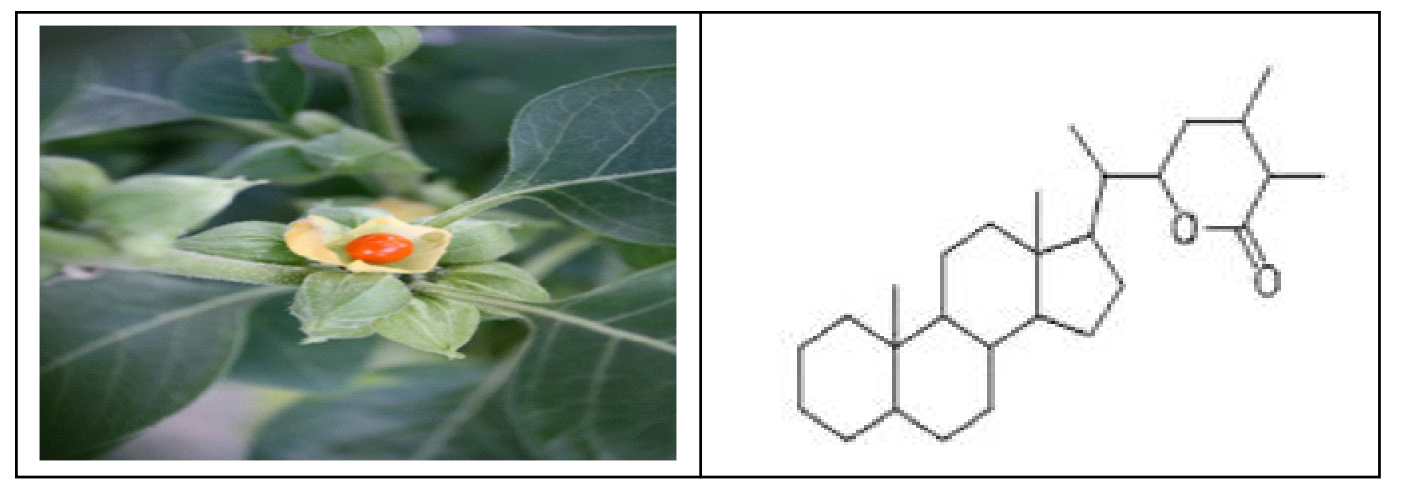

Figure 3: (A) Withania somnifera (B) Basic withanoid structure.

\section{3. (a) Chemistry of W. somnifera}

The extract of W. somnifera is a complex mixture composed of numerous phytochemicals including steroids, salts, flavonoids, alkaloids, steroidal lactones and nitrogen containing compounds. More than 40 withanolides (Figure 3 B), 12 alkaloids and several sitoindosides have been isolated and reported in this plant. Among these, phytochemicals the major pharmacological effects are ascribed to withanolides (Dar et al., 2015). The active constituents and metabolites of W. somnifera are: Withanolide A \& B, sominone, withanone, witheferin A, withanoside 4 and 5, withanolide Q and ashwagandhanolide (Dar, 2020).

\section{3. (b) Biological role of Withania somnifera}

Different cellular and animal models study have demonstrated that the extract, constituents and the metabolites of W. somnifera possess antioxidant properties and rescue neuronal cells against toxic insults by modulating PI3K/MAPK/Akt signaling pathways. They also possess antiapoptotic cascades, hence has the potential to protect the neurons from degenerative conditions such as in diseases like Parkinson, Huntington and Alzheimer diseases. A big hurdle for its clinical use against these diseases is blood brain barrier permeability of its active constituents. Therefore, direct injections into brain or nanotechnological approaches can be done to achieve its clinical use (Dar, 2020). A lot of studies have been done with extract of different parts of this plant to cure Parkinson's disease 
(Ahmad et al., 2005) used root extract and they found that root extract attenuated 6-OHDA neurotoxicity in rat model. Extract of active constituent of $W$. somnifera attenuated oxidative stress, restored level of dopamine, improved impaired cholinergic function and mitochondrial respiratory mechanisms, thereby reducing locomotors defects and lethality (Manjunath, 2015). In one study (Dar et al., 2017) it was proved that this plant work as an antiplatelet aggregatory, anxiolytic, anticonculsive, anti-inflammatory, and hence as neuroprotective agent. Ahmed et al. (2013) used active constituents in PD rat model and found that the number of surviving dopaminergic neurons increased and also pathology significantly reduced. The leaf extract reduced the oxidative stress and modulated physiological abnormalities whereas root extract improved catecholamines in MPTP induced PD rat model (Rajasankar et al., 2009; Rajasankar et al., 2009). Its root extract was found to regulate D2 dopaminergic receptor numbers also in striatum neurons, it also attenuated the apoptotic signals in the dopaminergic neurons also reduced oxidative impairments and restored mitochondrial respiratory chain enzymes and increased the expression of tyrosine hydroxylase (Nagashayana et al., 2000; Kumar et al., 2011; Prakash et al. 2014; Manjunath, 2015). Manjunath (2015) used root powder, extract of W. somnifera in rotenone induced PD rat model and found that after intervention of root powder the toxicity of rotenone decreased significantly.

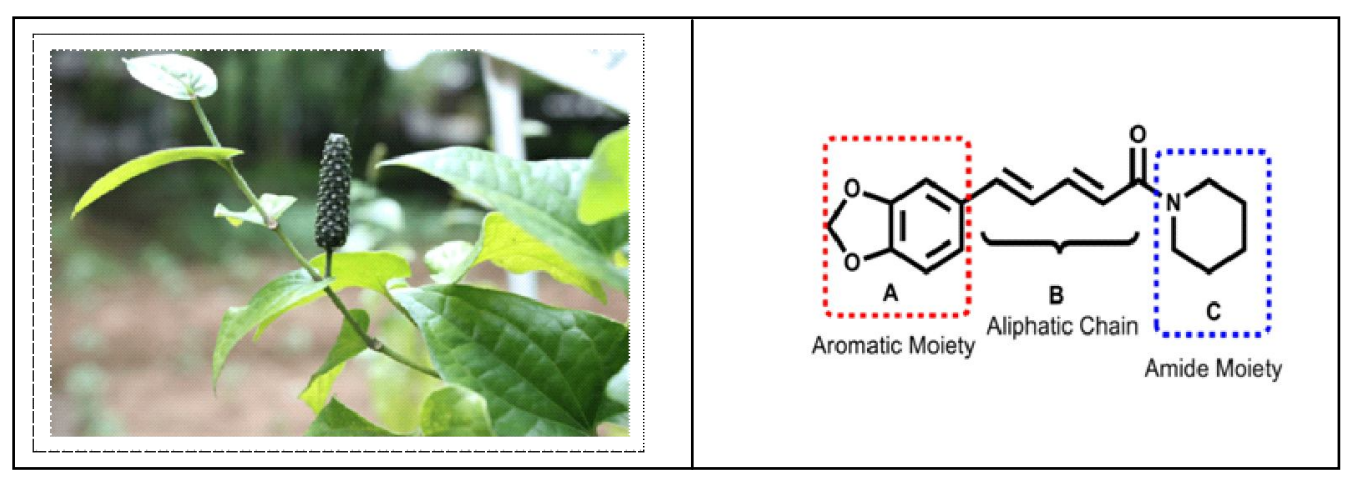

Figure 4: (A) Piper longum L. (B) Piperine.

\section{Piper longum $\mathrm{L}$.}

Piper longum (L.) (Figure 4. A), a native of the Indo-Malayan region, has been widely used in the traditional medicine in Asia and Pacific Islands as analgesic (Kumar et al., 2011). It is known as Pippali in Ayurveda (Soni et al., 2011). P. longum belongs to Piperaceae family. Piperine (Figure 4. B) is the major effective constituent of $P$. longum. Piperine possess a role that it can be used as potential bioavailibity enhancer of drugs used in the management of various diseases, bioenhancers are agents capable of increasing bioavailabilty when combined with a particular therapeutic agent without exerting any of its biological activity at the used dose. It might enhance the absorption and bioavailability of drugs probably by its effect on intestinal brush border morphologically (Han, 2011; Johnson et al., 2011). The term bioenhancer/biopotentiator was first defined by an Indian scientist Dr. C.K. Atal at Regional Research Laboratory (RRL, Jammu), currently known as the Indian Institute of Integrative Medicine, Jammu, India (Dudhatra et al., 2012). Bioenhancers are capable of increasing the absorption from the gastrointestinal tract or inhibiting enzymes involved in the biotransformation of the drug by preventing the drug transformation to metabolites and by decreasing the rate of elimination (Khatri $e t$ al., 2015; Prasad et al., 2016; Khatri and Awasthi, 2016). Along with the bioenhancing effect, it has multiple biological properties also, e.g., anti-inflammatory, antianxiety effects, antiHBV activity, anticancer, antioxidative. P. longum is well reported in Indian medicine for the treatment of diseases such as cancer, asthma, depression, rheumatoid arthritis, inflammation, pain management, depression, influenza, fever and infectious diseases (Pardeep and Kuttan, 2002; Parthasarathy , 2008; Correa et al., 2010; Jiang et al., 2013; Bi et al., 2015). It is widely used as an analgesic and it is reported that piperine can be used for the enhancement of stimulation of appetite, salivation and blood circulation (Meghwal et al., 2021). It also acts on many enzyme systems, e.g., pglycoproteins (Li et al., 2011; Meghwal et al., 2021).

\section{4. (a) Chemistry of $P$. longum}

Alkaloids of $P$. longum called as PLA and it includes piperine and piper longuminine. These alkaloids have multiple biological properties such as antioxidative, anti-inflammatory, antianxiety, etc. Its fruit contains numerous alkaloids and related compounds among which, piperine is most abundant. PLA is extracted from seeds of P. longum which contain 4-5\% piperine, the amount of piperine content can be influenced by alterations in conditions of cultivation such as drying conditions, climate and the place of origin (Sozzi et al., 2012). Piperine is basic (weak) in nature which upon hydrolysis converted into piperidine and piperic acid, IUPAC name of piperine is (2E, 4E)-5-(benzo[d] [1,3]dioxol-5-yl)1-(piperidin1-yl)penta-2,4-dien-1- one (Pruthi, 1999). A conjugated aliphatic chain acts as a bridging connective structure between piperidine and 5-(3,4-methylenedioxyphenyl) moiety which makes piperine a unique and excellent molecule to offer optimum attributes for the tendency of the molecule to bind successfully to the CYP- 450 enzymes (Bang et al., 2009)

\section{4. (b) Biological role of $P$. longum}

It is indicated (Lee et al., 2006) that piperine attenuate viability loss of MPTP-induced PC12 cells by suppressing the mitochondrial membrane permeability transition, leading to the activation of caspase-3. A lot of studies have examined neuroprotective functions of PLA in PD models. An in vivo study with mouse model of PD was done to demonstrate the protective effects of PLA against MPTPinduced dopaminergic neuronal cell death. This study provided some evidences that PLA protected dopaminergic cells from MPTP neurotoxicity by ameliorating behavioral abnormalities, reducing 
loss of TH-positive neurons in substantia nigra, increasing levels of DA and its associated metabolites, and enhancing antioxidative defence system by increasing enzymes activity, e.g., GSH and SOD activity, resulted into decreased MDA levels. The phytochemicals of $P$. longum, e.g., alkaloids possess protective effects in PD models including MPTP, 6-OHDA rat/mouse models (Zaveri et al., 2010; Subburaman et al., 2010; Liu et al., 2011). It was reported (Pal and Choudhary, 2012) the effect of piperine on 3T3-L1 cell lines by inhibiting the expression of PPAR- $\gamma$, thus it can be used in treatment of various diseases. Piperine have the ability to inhibit intestinal and hepatic hydroxylation and glucuronidation of aryl-hydrocarbon, thus preventing the degradation of drugs in the gut and improve their bioavailability. For example, co-administration of piperine enhances the bioavailability of curcumin in vivo by $2000 \%$ in humans and $154 \%$ in rats (Zaveri et al., 2010). Studies have shown that curuminderivatized with piperic acid (obtained by the base hydrolysis of piperine) forming di-piperoylcurcu-mindiester, showed improved protection against oxidative and nitrosative stress in vitro and against toxin induced cell death in dopaminergic cells (Harish et al., 2010; Mythri et al., 2011). Thus, the use of such pro-drugs with improved cellular uptake would be beneficial in targeting the degenerative processes involved in neurodegenerative diseases such as PD. Although, the neuroprotective applications of $P$. longum in isolation have not been patented; several formulations have been described which include the use of the dried seed powder of $P$. longum in combination with other natural products. US6106839 patent describes the use of $P$. longum powder (10-35\% by weight) along with cowhage (55-99\% by weight) and ginger (5-15\% by weight) to treat PD (Pruthi and Pruthy, 2000).

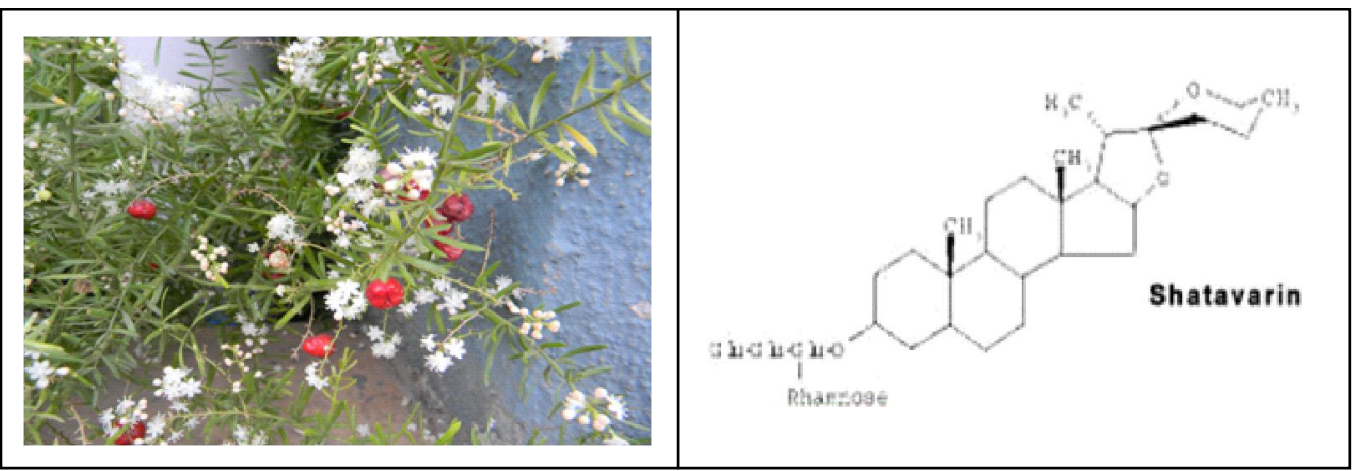

Figure 5: (A) Asparagus racemosus L. and (B) Shatavarin.

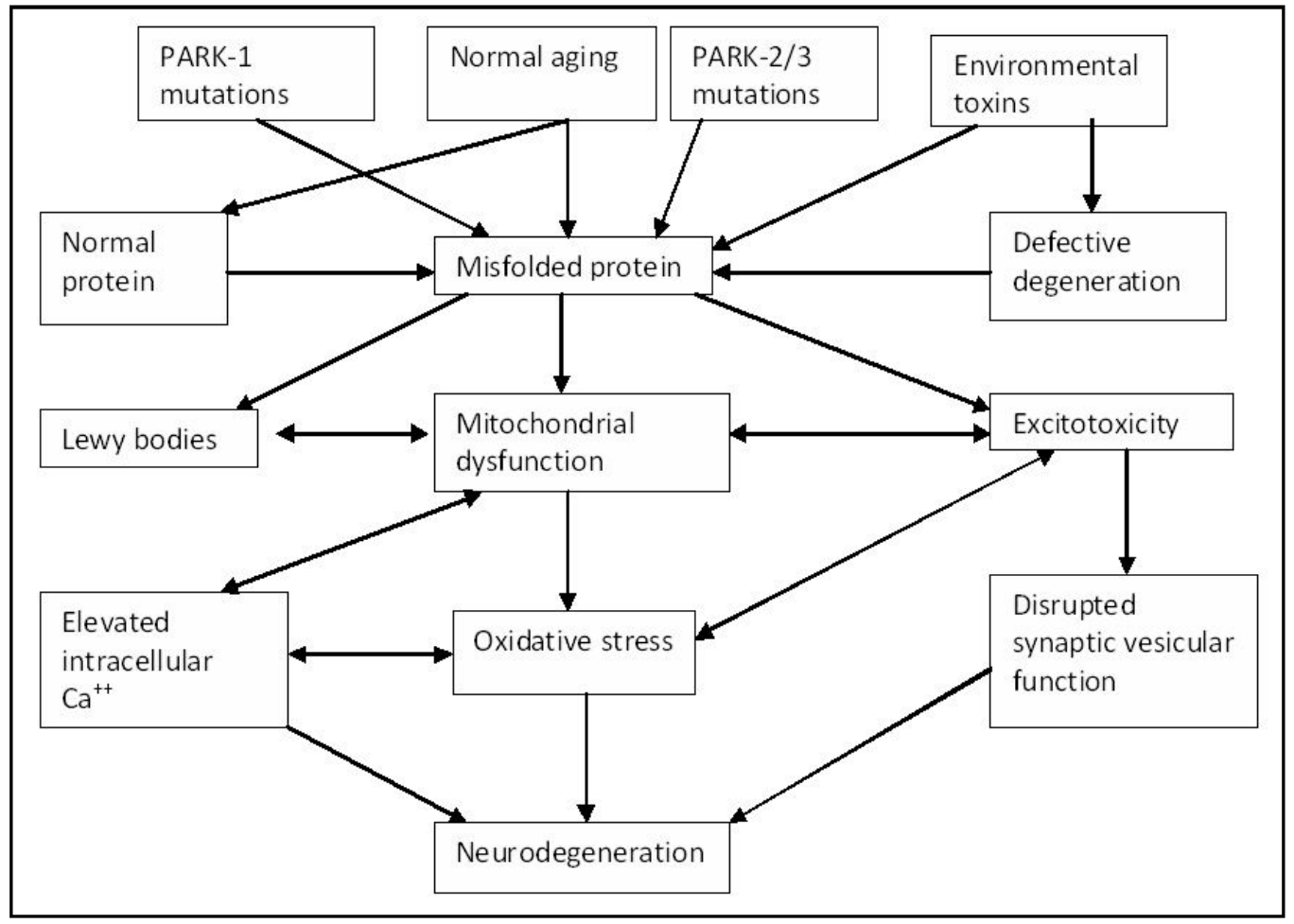

Figure 6: The putative pathomechanism of Parkinson's disease. Both environmental and genetic factors can initiate a cascade of molecular steps, which lead to excitotoxicity, mitochondrial dysfunction, oxidative stress and ultimately cell death. 


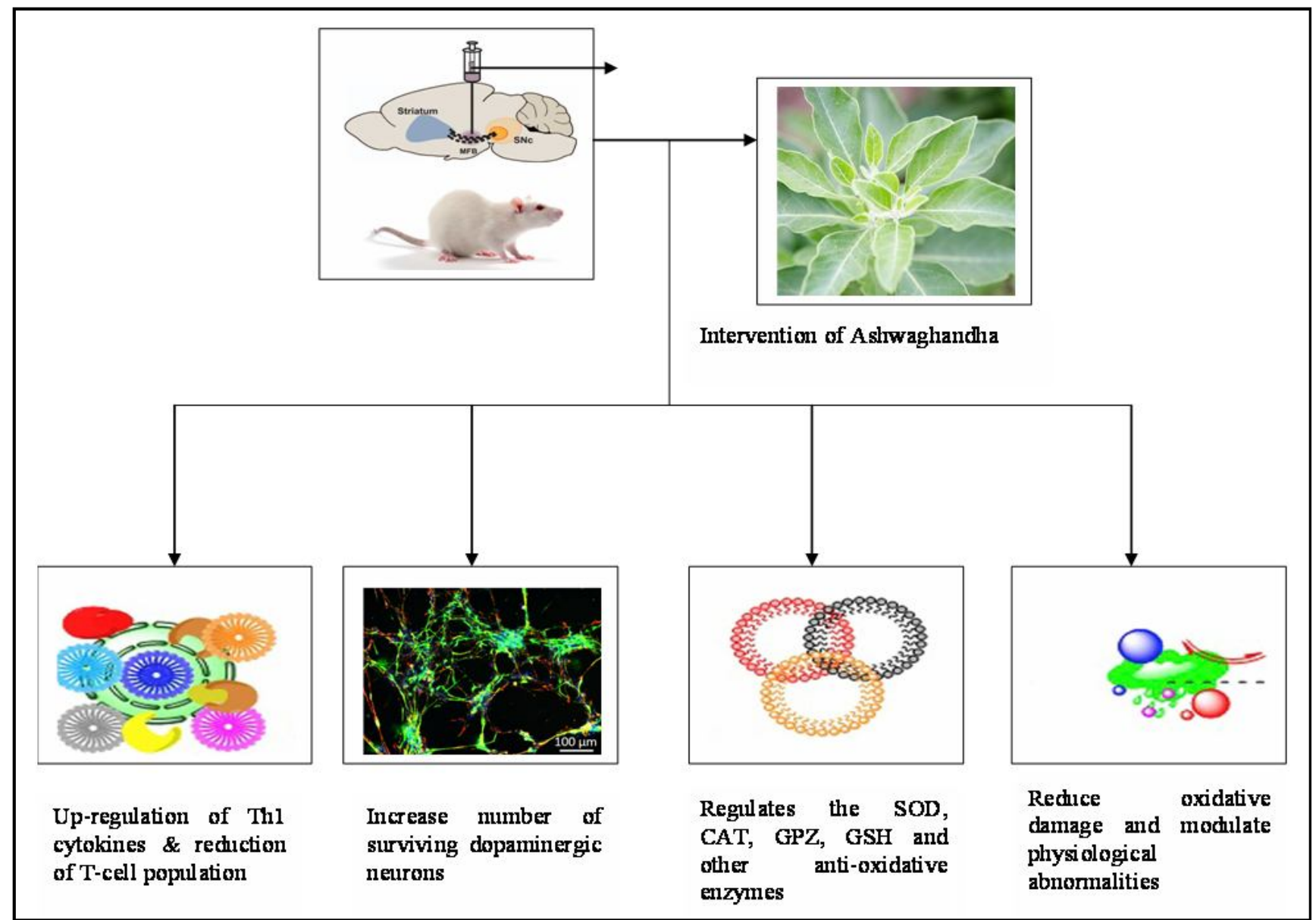

Figure 7: Graphical depiction of neuroprotective effects of W. somnifera (L.): W. somnifera extracts and its active constituents have demonstrated to possess antioxidant properties, rescue of neuronal cells against toxic insults, by regulating different antioxidant enzymes, lipid-peroxidation processes in Parkinson's disease.

\section{Asparagus racemosus}

Asparagus racemosus (Figure 4. A) traditionally known as "Shatavari"- a herb which is highly effective in curing the problems related with female reproductive system and is found at low altitude throughtout India (Hasan et al., 2016). The two main texts on Ayurvedic medicines, i.e., Charak Samhita and Ashtang Hridyam, written by Charak and Vagbhata, respectively, lists A. racemosus as part of various formulas used to treat disorders affecting women's health (Thorne, 2000). It belongs to Asparagaceae family. A. racemosus used as medicine in Ayurveda, Siddha and Unani system and in modern Ayurveda its roots are used as drug and considered to be effective in night blindness, blood purifying, kidney problems, throat complaints, nervous disorder and it acts as antidysentriric, anti-inflammatory, antidiarrheal, antitubercular, antiepileptic, antispasmodic, laxative, appetizer and as a female tonic also (Thakur et al., 2018). A. racemosus is mentioned as medhya-the plants which promote learning and memory also increase intelligence (Ojha et al., 2010) and as rejuvenator herbs which improve health by increasing viability, resistance and immunity, also imparting longevity as well as protection against stress.

\section{5. (a) Chemistry of A. racemosus}

Approximately 300 species of Asparagus are distributed around the world, and among these, 22 species have been recorded in India where, A. racemosus is most commonly used as a medicinal plant in traditional medicine (Bopana and Saxena, 2007). The content of Shatavari (Figure 5. B) are flavonoids (quercetin, rutin and kaempferol), sapgenin, sarsasapogenins and polyphenols and these polyphenols are the precursor of many pharmacologically active steroids. Its various parts possess a wide range of phytochemical constituent, e.g., Shatavari roots contain four steroids saponin known as shatvarins (shatvarin I to IV). Shatvarin I is the major glycoside with rhamnose and 3-glucose moieties attached to sarsapogenin, wherein shatvarin IV one rhamanose and two glucose moieties are attached. Shatavarin V, curillins, curillosides, asparosides and Asparginins have also been reported recently (Patricia et al., 2006). The oligo-spirostanoside is also present which is refrred to as immunoside (Handa et al., 2003) and polycyclic alkaloid - aspargamine A. (a cage type pyrrolizidine alkaloid) are also present. A. racemosus has various components such as furan compound- racemofuran (Kamat et al., 2000), isoflavones-8methoxy- 5, 6, 4-trihydroxy isoflavone-7-0-beta-D-glucopyranoside (Saxena and Chaurasia, 2001), cyclic hydrocarbon-racemosol (Wiboonpun et al., 2004), carbohydrates-polysaccharides, mucilage and in flower and fruits flavanoids (glycosides of rutin, hyperoside and quercitin) are present (Singh, 2007). Essential fatty acids such as gamma linolenic acids, diosgenin, glucourbnides, quercetin and vitamin A are found in it, and its woody portion of tuberous roots 
have kaepfrol along with sarsapogenin. Its roots have various sterols, e.g., benzaldehyde, sitosterol and undecanylcetanoate and also trace minerals, e.g., manganeese, copper, cobalt, zinc along with potassium, selenium and magnesium (Mohanat et al., 2003; Gadade and Patil, 2019).

\section{5. (b) Biological role of A. racemosus}

A. racemosus inhibited acetylcholinesterase enzyme in specific brain regions (prefrontal cortex, hippocampus and hypothalamus). Thus, it shows antiamnesic and nootropic activities in the models tested and these effects may be mediated through augmentation of cholinergic system due to its anticholinesterase activity and $A$. racemosus extract verified that significant decrease in latency time during retention trials. Hippocampal regions associated with the learning and memory functions and show dose dependent increase in acetylecholinstrase activity in carbonic anhydrase-1 with $A$. racemosus (Ojha et al., 2010, Sharma et al., 2010). Parihar and Hemnani (2004) conducted a study to investigate the potential of methanolic extract of $A$. racemosus roots against kainic acid (KA)induced hippocampal and striatal neuronal damage in mice. Intrahippocampal and intra-striatal injections of KA to anesthetized mice resulted in the production of excitotoxic lesions in the brain. After KA injection, impairment of hippocampus and striatal regions of brain was observed accompanied by increased lipid peroxidation, increased protein carbonyl content, decreased glutathione peroxidase (GPx) activity and reduced glutathione hormone (GSH) content. GSH is an important antioxidant which acts as a nucleophilic scavenger of toxic compounds and as a substrate in the GPx-mediated destruction of hydroperoxides which would otherwise accumulate to toxic levels in brain tissues. The mice treated with A.racemosus extract showed an enhancement in GPx activity and GSH content, and reduction in membranal lipid peroxidation and protein carbonyl. It is concluded that the plant extract plays the role of an antioxidant by attenuating free radical induced oxidative damage (Bhattacharya et al., 2002).

\section{Conclusion}

Currently, the CNS diseases, in particular the neurodegenerative disorders, constitute a serious health problem increasingly affecting the global population, involving a great morbidity and mortality. The current treatments available in clinics alleviate symptoms, but do not minimize the pathological conditions associated to these diseases. For example, the neuronal cells degeneration and the loss of dopamine production, in Parkinson's disease, thereby, for this disorder, there is a decrease of neurons, which are related to the loss of physiological, cognitive and intellectual functions, originating dementia. The complex organization and structure of the brain, as well as the existence of physiological barriers, such as the BBB and the blood-CSF barrier, difficult the delivery of drugs directly to the CNS, also these drugs have several side effects, along with lack of therapeutic efficacy. To overcome these drawbacks, several alternatives to conventional treatments have been developed. Among these, the most promising is the use of traditional medicines (e.g., Neem, Karela, Pipalli, etc.). The progresses that have been made in this area outline the possibility of this application for the treatment of Parkinson's disease, in a near future, although more studies are needed.

\section{Conflicts of interest}

The authors declare no conflicts of interest relevant to this article.

\section{References}

Ahmad, M.; Saleem, S.; Ahmad, A.S.; Ansari, M.A.; Yousuf, S.; Hoda, M.N. and Islam, F. (2005). Neuroprotective effects of Withania somnifera on 6-hydroxydopamine induced Parkinsonism in rats. Human and Experimental Toxicology, 24(3):137-147.

Ahmed, M.E.; Javed, H.; Khan, M.M.; Vaibhav, K.; Ahmad,A.; Khan, A.; Tabassum, R.; Islam, F.; Safhi, M.M. and Islam, F. (2013). Attenuation of oxidative damage-associated cognitive decline by Withania somnifera in rat model of streptozotocin-induced cognitive impairment. Protoplasma, 250(5):1067-1078.

Al-Snafi, A.E. (2015). Therapeutic properties of medicinal plants: A review of medicinal plants with central nervous effects (part 1). Int. J. of Pharmacology and Toxicology, 5(3):177-192.

Amagase, H. (2006). Clarifying the real bioactive constituents of garlic. The Journal of Nutrition, 136(3):716S-725S.

Amantea, D.; Nappi, G.; Bernardi, G.; Bagetta, G. and Corasaniti, M.T. (2009). Post ischemic brain damage: Pathophysiology and role of inflammatory mediators. The FEBS Journal, 276(1):13-26.

Baker, S.A.; Baker, K.A. and Hagg, T. (2005). D3 dopamine receptors do not regulate neurogenesis in the subventricular zone of adult mice. Neurobiology of Disease, 18(3):523-527.

Bang, J.S.; Oh, D.H.; Choi, H.M.; Sur, B.J.; Lim, S.J.; Kim, J.Y.; Yan, H.I.; Yoo, M.C.; Hahm, D.H. and Kim, K. S. (2009). Anti-inflammatory and antiarthritic effects of piperine in human interleukin $1 \beta$-stimulated fibroblastlike synoviocytes and in rat arthritis models. Arthritis Research and Therapy, 11(2): 1-9.

Bhattacharya,A.; Muruganandam, A.V.; Kumar, V. and Bhattacharya, S.K. (2002). Effect of poly herbal formulation, EuMil, on neurochemical perturbations induced by chronic stress. Review, 9(1):20.

Bi, Y.; Qu, P.C.; Wang, Q.S.; Zheng, L.; Liu, H. L.; Luo, R.; Chen, X.Q.; Ba, Y.Y.; Wu, X. and Yang, H. (2015). Neuroprotective effects of alkaloids from Piper longum in a MPTP-induced mouse model of Parkinson's disease. Pharmaceutical Biology, 53(10):1516-1524.

Biswas, K.; Chattopadhyay, I.; Banerjee, R.K. and Bandyopadhyay, U. (2002). Biological activities and medicinal properties of neem (Azadirachta indica). Current Science, 1336-1345.

Blasi, P.; Giovagnoli, S.; Schoubben, A.; Ricci, M. and Rossi, C. (2007). Solid lipid nanoparticles for targeted brain drug delivery. Advanced Drug Delivery Reviews, 59(6):454-477.

Bloem, B.R.; Hausdorff, J.M.; Visser, J.E. and Giladi, N. (2004). Falls and freezing of gait in Parkinson's disease: A review of two interconnected, episodic phenomena. Movement Disorders: Official Journal of the Movement Disorder Society, 19(8):871-884.

Bopana, N. and Saxena, S. (2007). Asparagus racemosus Ethnopharmacological evaluation and conservation needs. Journal of Ethnopharmacology, 110(1):1-15.

Brahmachari, G. (2004). Neem: An omnipotent, Chembiochem, 5: 408421.

Cenci, M.A. (2014). Presynaptic mechanisms of 1-DOPA-induced dyskinesia: The findings, the debate, and the therapeutic implications. Frontiers in Neurology, 5:242.

Chan, W.S.; Durairajan, S.S.K.; Lu, J.H.; Wang, Y.; Xie, L.X.; Kum, W.F.; Koo, I.; Yung, K.K.L. and Li, M. (2009). Neuroprotective effects of Astragaloside IV in 6-hydroxydopamine-treated primary nigral cell culture. Neurochemistry International, 55(6):414-422. 
Chen, L.W.; Wang, Y.Q.; Wei, L.C.; Shi, M. and Chan, Y.S. (2007). Chinese herbs and herbal extracts for neuroprotection of dopaminergic neurons and potential therapeutic treatment of Parkinson's disease. CNS \& Neurological Disorders-Drug Targets (Formerly Current Drug Targets-CNS \& Neurological Disorders), 6(4):273-281.

Connolly, B.S. and Lang, A.E. (2014). Pharmacological treatment of Parkinson disease: A review. Jama, 311(16):1670-1683.

Correa, E.A.; Högestätt, E.D.; Sterner, O.; Echeverri, F. and Zygmunt, P.M. (2010). In vitro TRPV1 activity of piperine derived amides. Bioorganic and Medicinal Chemistry, 18(9):3299-3306.

Cui, Z.; Lockman, P.R.; Atwood, C.S.; Hsu, C.H.; Gupte, A.; Allen, D.D. and Mumper, R.J. (2005). Novel D-penicillamine carrying nanoparticles for metal chelation therapy in Alzheimer's and other CNS diseases. European Journal of Pharmaceutics and Biopharmaceutics, 59(2):263-272.

Dar, N. J.; Hamid, A. and Ahmad, M. (2015). Pharmacologic overview of Withania somnifera, the Indian Ginseng. Cellular and Molecular Life Sciences, 72(23):4445-4460.

Dar, N.J. (2020). Neurodegenerative diseases and Withania somnifera (L.): An update. Journal of Ethnopharmacology, 256:112769.

Dar, N.J.; Bhat, J.A.; Satti, N.K.; Sharma, P.R.; Hamid,A. and Ahmad, M. (2017) Withanone, an active constituent from Withania somnifera, affords protection against NMDA-induced excitotoxicity in neuron-like cells. Molecular Neurobiology, 54(7):5061-5073.

Dawson, T.M. and Dawson, V.L. (2003). Molecular pathways of neurodegeneration in Parkinson's disease. Science, 302(5646):819822 .

Devos, D.; Defebvre, L. and Bordet, R. (2010). Dopaminergic and nondopaminergic pharmacological hypotheses for gait disorders in Parkinson's disease. Fundamental and Clinical Pharmacology, 24(4): 407-421.

Dexter, D.T. and Jenner, P. (2013). Parkinson disease: From pathology to molecular disease mechanisms. Free Radical Biology and Medicine, 62:132-144.

Dudhatra, GB., Mody, S.K.,Awale, M.M., Patel, H.B., Modi, C.M., Kumar,A., Kamani, D.R. and Chauhan, B.N. (2012). A comprehensive review on pharmacotherapeutics of herbal bioenhancers. The Scientific World Journal, 2012.

Dzamko, N.; Zhou, J.; Huang, Y. and Halliday, G.M. (2014). Parkinson's diseaseimplicated kinases in the brain; insights into disease pathogenesis. Frontiers in Molecular Neuroscience, 7:57.

Dziri, S.; Hassen, I.; Fatnassi, S.; Mrabet, Y.; Casabianca, H.; Hanchi, B. and Hosni, K. (2012). Phenolic constituents, antioxidant and antimicrobial activities of rosy garlic (Allium roseum var. odoratissimum). Journal of Functional Foods, 4(2):423-432.

Fink, A.L. (2006). The aggregation and fibrillation of $\alpha$-synuclein. Accounts of Chemical Research, 39(9):628-634.

Gadade, J.P. and Patil, S.A. (2019). Phytochemical paradigm, antioxidan status and their correlation in Rotheca serrata (L.) Steane and Mabb. Ann. Phytomed., 8(2):156-166.

Gao, Q.G.; Chen, W.F.; Xie, J.X. and Wong, M.S. (2009). Ginsenoside Rg1 protects against 6 OHDA induced neurotoxicity in neuroblastoma SK N SH cells via IGF I receptor and estrogen receptor pathways. Journal of Neurochemistry, 109(5):1338-1347.

Gaur, V.; Bodhankar, S.L.; Mohan, V. and Thakurdesai, P.A. (2013). Neurobehavioral assessment of hydroalcoholic extract of Trigonella foenum graecum seeds in rodent models of Parkinson's disease. Pharmaceutical Biology, 51(5):550-557.

Gong, J.; Sun, F.; Li, Y.; Zhou, X.; Duan, Z.; Duan, F.; Zhao, L.; Chen, H.; Qi, S. and Shen, J. (2015). Momordica charantia polysaccharides could protect against cerebral ischemia/reperfusion injury through inhibiting oxidative stress mediated c-Jun N-terminal kinase 3 signaling pathway. Neuropharmacology, 91:123-134.
Guo, D.; Zhou, J.; Zhang, M.; Taximaimaiti, R.; Wang, X. and Wang, H. (2021). Momordica charantia polysaccharides attenuates MPP+-Induced injury in parkinson's disease mice and cell models by regulating TLR4/MyD88/NF- $\kappa \mathrm{Bj}$ Pathway. International Journal of Polymer Science, 2021

Gupta, S.C.; Prasad, S.; Reuter, S.; Kannappan, R.; Yadav, V.R.; Ravindran, J.; Hema, P.S.; Chaturvedi, M.M.; Nair, M. and Aggarwal, B.B. (2010). Modification of cysteine 179 of I $\mathrm{B} \alpha$ kinase by nimbolide leads to down-regulation of NF- $\kappa \mathrm{B}$-regulated cell survival and prolifera-tive proteins and sensitization of tumor cells to chemotherapeutic agents. Journal of Biological Chemistry, 285(46):35406-35417.

Gupta, S.C.; Prasad, S.; Tyagi, A.K.; Kunnumakkara, A.B. and Aggarwal, B.B. (2017). Neem (Azadirachta indica): An indian traditional panacea with modern molecular basis. Phytomedicine, 34:14-20.

Han, H.K. (2011). The effects of black pepper on the intestinal absorption and hepatic metabolism of drugs. Expert Opinion on Drug Metabolism and Toxicology, 7(6):721-729.

Handa, S.S.; Suri, O.P.; Gupta; V.N.; Suri, K.A.; Satti, N.k.; Bhardwaj, V.; Bedi, K.L.; Khajuria, A.; Kaul, A.; Parikh, G.G and Kulhar P. (2003). Process for the Isolation of novel oligospirostanoside. U.S. Patent 6,670,459. Washington, DC:U.S. Patent and Trademark Office.

Hao, F.; Kumar, S.; Yadav, N. and Chandra, D. (2014). Neem components as potential agents for cancer prevention and treatment. Biochimica et Biophysica Acta (BBA)-Reviews on Cancer, 1846(1):247-257.

Harish, G., Venkateshappa, C., Mythri, R.B., Dubey, S.K., Mishra, K., Singh, N., Vali, S. and Bharath, M.S. (2010). Bioconjugates of curcumin display improved protection against glutathione depletion mediated oxidative stress in a dopaminergic neuronal cell line: implications for Parkinson's disease. Bioorganic and Medicinal Chemistry, 18(7):2631-2638.

Hasan, N.; Ahmad, N.; Zohrameena, S.; Khalid, M. and Akhtar, J. (2016). Asparagus racemosus: For medicinal uses and Pharmacological actions. Int. J. Adv. Res, 4:259-267.

Hatti, K.S.; Muralitharan, L.; Hegde, R. and Kush, A. (2014). NeeMDB: convenient database for neem secondary metabolites. Bioinformation, 10(5):314.

Höglinger, G.U.; Rizk, P.; Muriel, M.P.; Duyckaerts, C.; Oertel, W.H.; Caille, I. and Hirsch, E.C. (2004). Dopamine depletion impairs precursor cell proliferation in Parkinson disease. Nature Neuroscience, 7(7);726735 .

Houghton, P.J. and Howes, M.J. (2005). Natural products and derivatives affecting neuro transmission relevant to Alzheimer's and Parkinson's Dsease. Neurosignals, 14(1-2):6-22.

Hu, S.; Han, R.; Mak, S. and Han, Y. (2011). Protection against 1-methyl-4phenylpyridinium ion (MPP+)-induced apoptosis by water extract of ginseng (Panax ginseng CA Meyer) in SH-SY5Y cells. Journal of Ethnopharmacology, 135(1):34-42.

Jia, S.; Shen, M.; Zhang, F. and Xie, J. (2017). Recent advances in Momordica charantia: Functional components and biological activities. International Journal of Molecular Sciences, 18(12):2555.

Jiang, Z.Y.; Liu, W.F.; Zhang, X.M.; Luo, J.; Ma, Y.B. and Chen, J.J. (2013). AntiHBV active constituents from Piper longum. Bioorganic and Medicinal Chemistry Letters, 23(7):2123-2127.

Johnson, J.J.; Nihal, M.; Siddiqui, I.A.; Scarlett, C.O.; Bailey, H.H.; Mukhtar, H. and Ahmad, N. (2011). Enhancing the bioavailability of resveratrol by combining it with piperine. Molecular Nutrition and Food Research, 55(8): $1169-1176$.

Kamat, J. P.; Boloor, K. K.; Devasagayam, T. P. and Venkatachalam, S. R. (2000). Antioxidant properties of Asparagus racemosus against damage induced by $\beta$-radiation in rat liver mitochondria. Journal of Ethnopharmacology, 71(3):425-435. 
Kang, J.; Zeng, B.; Tang, S.; Wang, M.; Han, X.; Zhou, C.; Yan, Q.; Liu, J. and Tan, Z. (2017). Effects of Momordica charantia polysaccharide on in vitro ruminal fermentation and cellulolytic bacteria. Italian Journal of Animal Science, 16(2):226-233.

Kango, S.; Kalia, S.; Celli, A.; Njuguna, J.; Habibi, Y. and Kumar, R. (2013). Surface modification of inorganic nanoparticles for development of organic-inorganic nanocomposites: A review. Progress in Polymer Science, 38(8):1232-1261.

Kedar, N.P. (2003). Can we prevent Parkinson's and Alzheimer's disease?. Journal of Postgraduate Medicine, 49(3):236.

Khatri, S. and Awasthi, R. (2016). Piperine containing floating microspheres an approach for drug targeting to the upper gastrointestinal tract. Drug Delivery and Translational Research, 6(3):299-307.

Khatri, S.; Ahmed, F.J. and Rai, P. (2015). Formulation and evaluation of floating gastroretentive capsules of acyclovir with piperine as a bioenhancer. The Pharma Innovation, 3(11, Part B):78.

Kim, I.S.; Koppula, S.; Park, P.J.; Kim, E.H.; Kim, C.G.; Choi, W.S.; Lee, K.L. and Choi, D.K. (2009). Chrysanthemum morifolium Ramat (CM) extract protects human neuroblastoma SH-SY5Y cells against MPP+-induced cytotoxicity. Journal of Ethnopharmacology, 126(3):447-454.

Kochhar, K.P. (2008). Dietary spices in health and diseases (II). Indian J. Physiol. Pharmacol., 52(4):327-354.

Kochhar, K.P. (2008). Dietary spices in health and diseases: I. Indian J. Physiol. Pharmacol., 52(2):106-122.

Kumar, G.P. and Khanum, F. (2012). Neuroprotective potential of phytochemicals. Pharmacognosy Reviews, 6(12):81.

Kumar, S.; Kamboj, J. and Sharma, S. (2011). Overview for various aspects of the health benefits of Piper longum linn. fruit. Journal of Acupuncture and Meridian Studies, 4(2):134-140.

Kumari, P.; Verma, R.B.; Nayik, G.A. and Solankey, S.S. (2017). Antioxidan potential and health benefits of Bitter gourd (Momordica charantia L.). Journal of Postharvest Technology, 5(3):1-8.

Lashuel, H.A.; Overk, C.R.; Oueslati, A. and Masliah E. (2013). The many faces of $\alpha$-synuclein: from structure and toxicity to therapeutic target. Nature Reviews Neuroscience, 14(1):38-48.

Lee, C.S.; Han, E.S. and Kim, Y.K. (2006). Piperine inhibition of 1-methyl-4phenylpyridinium-induced mitochondrial dysfunction and cell death in PC12 cells. European Journal of Pharmacology, 537(1-3):3744.

Li, S.; Lei, Y.; Jia, Y.; Li, N.; Wink, M. and Ma, Y. (2011). Piperine, a piperidine alkaloid from Piper nigrum re-sensitizes P-gp, MRP1 and BCRP dependent multidrug resistant cancer cells. Phytomedicine, 19(1):83-87.

Liu, J.; Bi, Y.; Luo, R. and Wu, X. (2011). Simultaneous UFLC-ESI-MS/MS determination of piperine and piperlonguminine in rat plasma after oral administration of alkaloids from Piper longum L.: Application to pharmacokinetic studies in rats. Journal of Chromatography B, 879(27):2885-2890.

Manjunath, M.J. (2015). Standardized extract of Withania somnifera (Ashwagandha) markedly offsets rotenone-induced locomotor deficits, oxidative impairments and neurotoxicity in Drosophila melanogaster. Journal of Food Science and Technology, 52(4):19711981.

Meghwal, M.; Devu, S.; Singh, H. and Goswami, T.K. (2021). Piperine and curcumin. In A Centum of Valuable Plant Bioactives Academic Press, 589-612.

Mu, X.; He, G.R.; Yuan, X.; Li, X.X. and Du, G.H. (2011). Baicalein protects the brain against neuron impairments induced by MPTP in C57BL/6 mice. Pharmacology Biochemistry and Behavior, 98(2): 286-291.
Mythri, R.B.; Harish, G.; Dubey, S.K.; Misra, K. and Bharath, M.S. (2011). Glutamoyl diester of the dietary polyphenol curcumin offers improved protection against peroxynitrite-mediated nitrosative stress and damage of brain mitochondria in vitro: Implications for Parkinson's disease. Molecular and Cellular Biochemistry, 347(1):135-143.

Nagashayana, N.; Sankarankutty, P.; Nampoothiri, M.R.V.; Mohan, P.K. and Mohanakumar, K.P. (2000). Association of L-DOPA with recovery following Ayurveda medication in Parkinson's disease. Journal of the Neurological Sciences, 176(2):124-127.

Newman, D.J. and Cragg, G.M. (2012). Natural products as sources of new drugs over the 30 years from 1981 to 2010. Journal of Natural Products, 75(3):311-335.

Nie, S.; Xu, Y.; Chen, G; Ma, K.; Han, C.; Guo, Z; Zhang, Z; Ye, K. and Cao, X. (2015). Small molecule TrkB agonist deoxygedunin protects nigrostriatal dopaminergic neurons from 6-OHDA and MPTP induced neurotoxicity in rodents. Neuropharmacology, 99:448-458.

Noelker, C.; Bacher, M.; Gocke, P.; Wei, X.; Klockgether, T.; Du, Y. and Dodel, R. (2005). The flavanoide caffeic acid phenethyl ester blocks 6hydroxydopamine-induced Neurotoxicity. Neuroscience Letters, 383(1-2):39-43.

Ojha, R.; Sahu, A.N.; Muruganandam, A.V.; Singh, G.K. and Krishnamurthy, S. (2010). Asparagus recemosus enhances memory and protects against amnesia in rodent models. Brain and Cognition, 74(1):1-9.

Olanow, C.W.; Obeso, J.A. and Stocchi, F. (2006). Continuous dopamine-receptor treatment of Parkinson's disease: Scientific rationale and clinical implications. The Lancet Neurology, 5(8):677-687.

Olanow, C.W.; Stern, M.B. and Sethi, K. (2009). The scientific and clinical basis for the treatment of Parkinson disease. Neurology, 72(21 Supplement 4):S1-S136.

Pal Singh, I. and Choudhary, A. (2015). Piperine and derivatives: Trends in structure-activity relationships. Current Topics in Medicinal Chemistry, 15(17):1722-1734.

Parthasarathy, V.A. (2008). Chempakam, B. and Zachariah, T.J. Chemistry of spices.

Patel, S.M.; Venkata, K.C.N.; Bhattacharyya, P.; Sethi, G. and Bishayee, A. (2016). Potential of neem (Azadirachta indica L.) for prevention and treatment of oncologic diseases. In Seminars in Cancer Biology Academic Press, 40:100-115.

Poewe, W.; Antonini, A.; Zijlmans, J.C.; Burkhard, P.R. and Vingerhoets, F. (2010). Levodopa in the treatment of Parkinson's disease: An old drug still going strong. Clinical Interventions in Ageing, 5:229.

Pradeep, C.R. and Kuttan, G. (2002). Effect of piperine on the inhibition of lung metastasis induced B16F-10 melanoma cells in mice. Clinical and Experimental Metastasis, 19(8):703-708.

Prakash, J.; Chouhan, S.; Yadav, S.K.; Westfall, S.; Rai, S.N. and Singh, S. P. (2014) Withania somnifera alleviates parkinsonian phenotypes by inhibiting apoptotic pathways in dopaminergic neurons. Neurochemical Research, 39(12):2527-2536.

Prakash, J.; Yadav, S.K.; Chouhan, S. and Singh, S.P. (2013). Neuroprotective role of Withania somnifera root extract in Maneb: Paraquat induced mouse model of parkinsonism. Neurochemical Research, 38(5):972980 .

Prasad, R.; Singh, A.; Gupta, N. and Tarke, C. (2016). Role of bioenhancers in tuberculosis. International Journal of Health Sciences and Research, 3076 .

Pruthi, S.C. and Pruthy, P. (2000). U.S. Patent No. 6,106,839. Washington, DC: U.S. Patent and Trademark Office.

Raish, M. (2017). Momordica charantia polysaccharides ameliorate oxidative stress, hyperlipidemia, inflammation, and apoptosis during myocardial infarction by inhibiting the NF- $\kappa \mathrm{B}$ signaling pathway. International Journal of Biological Macromolecules, 97:544-551. 
Raish, M.; Ahmad, A.; Ansari, M.A.; Alkharfy, K.M.; Aljenoobi, F.I.; Jan, B.L.; AlMohizea, A.M.; Khan, A. and Ali, N. (2018). Momordica charantia polysaccharides ameliorate oxidative stress, inflammation, and apoptosis in ethanol-induced gastritis in mucosa through NF-kB signaling pathway inhibition. International Journal of Biological Macromolecules, 111:193-199.

RajaSankar, S.; Manivasagam, T. and Surendran, S. (2009). Ashwagandha leaf extract: A potential agent in treating oxidative damage and physiological abnormalities seen in a mouse model of Parkinson's disease. Neuroscience Letters, 454(1):11-15.

RajaSankar, S.; Manivasagam, T.; Sankar, V.; Prakash, S.; Muthusamy, R.; Krishnamurti, A. and Surendran, S. (2009). Withania somnifera root extract improves catecholamines and physiological abnormalities seen in a Parkinson's disease model mouse. Journal of Ethnopharmacology, 125(3):369-373.

Rex, B.; Prabhu, S. and Kumar, J.S. (2019). Antifungal efficacies of plant extracts against Alternaria solani (Elis and Martin ) jones and groutnder in vitro codition. Ann. Phytomed., 8(1):1-5.

Saxena, V. K. and Chourasia, S. (2001). A new isoflavone from the roots of Asparagus racemosus. Fitoterapia, 72(3):307-309.

Schapira, A.H. and Olanow, C.W. (2004). Neuroprotection in Parkinson disease: mysteries, myths, and misconceptions. Jama, 291(3):358364 .

Schneider, J.S.; Gonczi, H. and Decamp, E. (2003). Development of levodopainduced dyskinesias in parkinsonian monkeys may depend upon rate of symptom onset and/or duration of symptoms. Brain Research, 990(1-2):38-44.

Siddiqui, B.S.; Ali, S.T. and Ali, S.K. (2009). Chemical wealth of Azadirachta indica (neem). Neem: A Treatise, IK International Publishing House Pvt Ltd., New Delhi, 171.

Singh, N.; Bhalla, M.; de Jager, P. and Gilca, M. (2011). An overview on ashwagandha: a Rasayana (rejuvenator) of Ayurveda. African Journal of Traditional, Complementary and Alternative Medicines, 8(5S).

Singh, S. (2007). From exotic spice to modern drug? Cell, 130(5): 765 768

Singh, U.P.; Maurya, S. and Singh, D.P. (2005). Phenolic acids in neem (Azadirachta indica) a major pre-existing secondary metabolites. Journal of Herbal Pharmacotherapy, 5(1):35-43.

Snee, L.S.; Nerurkar, V.R.; Dooley, D.A.; Efird, J.T.; Shovic,A.C. and Nerurkar, P.V. (2011). Strategies to improve palatability and increase consumption intentions for Momordica charantia (bitter melon): A vegetable commonly used for diabetes management. Nutrition Journal, 10(1):111 .

Soni, A.; Patel, K. and Gupta, S.N. (2011). Clinical evaluation of vardhamana pippali rasayana in the management of amavata (rheumatoid arthritis). Ayu, 32(2): 177 .

Sozzi, G.O.; Peter, K.V.; Babu, K.N. and Divakaran, M. (2012). Capers and caperberries. In handbook of herbs and spices, Woodhead Publishing, 193-224.

Spencer, J.P. (2009). The impact of flavonoids on memory: physiological and molecular considerations. Chemical Society Reviews, 38(4): 1152-1161

Stayte, S. and Vissel, B. (2014). Advances in non-dopaminergic treatments for Parkinson's disease. Frontiers in Neuroscience, 8:113.

Subapriya, R. and Nagini, S. (2005). Medicinal properties of neem leaves: a review. Current Medicinal Chemistry-AntiCancer Agents, 5(2):149156.
Subburaman, T.T.; Sampath, U. and Janardhanam, V.A. (2010). Neuroprotective action of Piper longum against MPTP-induced changes in mouse brain. Annals of Neurosciences, 17(1):18-21.

Sun, C.; Lee, J.S. and Zhang, M. (2008). Magnetic nanoparticles in MR imaging and drug delivery. Advanced Drug Delivery Reviews, 60(11):12521265 .

Tan, H.F. and Gan, C.Y. (2016). Polysaccharide with antioxidant, $\alpha$-amylase inhibitory and ACE inhibitory activities from Momordica charantia. International Journal of Biological Macromolecules, 85: 487-496.

Thakur, K.; Navdeep, A.; Jaswal, S. and Bhatt, A.K. (2018). Evaluation of antimicrobial potential of root extract of Asparagus racemosus Wild and bark extract of Juglans regia L. against pathogenic bacterial isolates. Ann. Phytomed., 7(2):64-69.

Thorne, R.F. (2000). Classification and geography of the flowering plants. The botanical review, 58(3):225-327.

Tosi, G.; Musumeci, T.; Ruozi, B.; Carbone, C.; Belletti, D.; Pignatello, R.; Vandelli, M.A. and Puglisi, G. (2016). The "fate" of polymeric and lipid nanoparticles for brain delivery and targeting: strategies and mechanism of blood-brain barrier crossing and trafficking into the central nervous system. Journal of Drug Delivery Science and Technology, 32:66-76.

Uddin, Q.; Samiulla, L.; Singh, V.K. and Jamil, S.S. (2012). Phytochemical and pharmacological profile of Withania somnifera Dunal: A review. J. Appl. Pharm. Sci., 2(01):170-175.

Vafeiadou, K.; Vauzour, D. and Spencer, J.P.E. (2007). Neuroinflammation and its modulation by flavonoids. Endocrine, metabolic and immune disorders-drug targets (Formerly current drug targets-immune, Endocrine and Metabolic Disorders), 7(3):211-224.

Van Kampen, J.M.; Hagg, T. and Robertson, H.A. (2004). Induction of neurogenesis in the adult rat subventricular zone and neostriatum following dopamine D3 receptor stimulation. European Journal of Neuroscience, 19(9):2377-2387.

Wiboonpun, N.; Phuwapraisirisan, P. and Tip pyang, S. (2004). Identification of antioxidant compound from Asparagus racemosus. Phytotherapy Research: An International Journal Devoted to Pharmacological and Toxicological Evaluation of Natural Product Derivatives, 18(9):771-773.

Xu, C.L.; Qu, R.; Zhang, J.; Li, L.F. and Ma, S.P. (2013). Neuroprotective effects of madecassoside in early stage of Parkinson's disease induced by MPTP in rats. Fitoterapia, 90: 112-118.

Xu, X.; Shan, B.; Liao, C.H.; Xie, J.H.; Wen, P.W. and Shi, J.Y. (2015). Anti-diabetic properties of Momordica charantia L. polysaccharide in alloxaninduced diabetic mice. International Journal of Biological Macromolecules, 81:538-543.

Yan, J.K. (2021). Three phase partitioning-based strategies for highly efficient separation of bioactive polysaccharides from natural resources. In Three Phase Partitioning Elsevier, 223-242.

Zaveri, M.; Khandhar, A.; Patel, S. and Patel, A. (2010). Chemistry and pharmacology of Piper longum L. International Journal of Pharmaceutical Sciences Review and Research, 5(1):67-76.

Zhang, C.; Wan, X.; Zheng, X.; Shao, X.; Liu, Q.; Zhang, Q. and Qian, Y. (2014). Dual-functional nanoparticles targeting amyloid plaques in the brains of Alzheimer's disease mice. Biomaterials, 35(1): 456-465. 